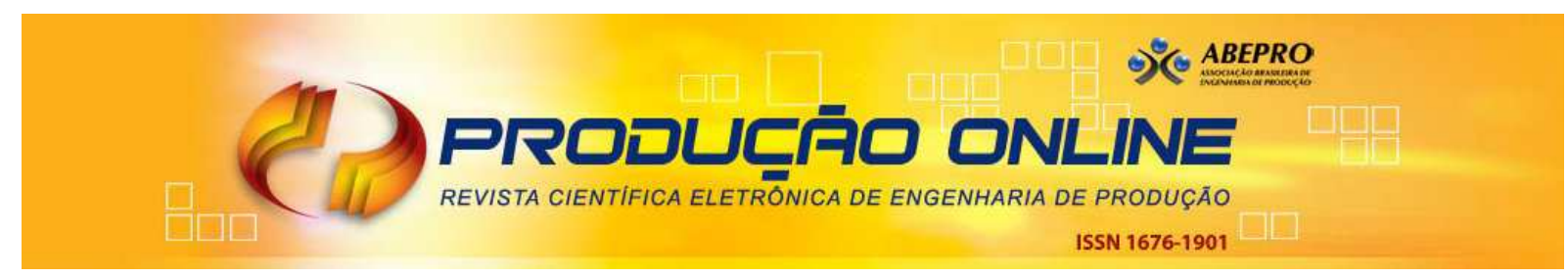

\title{
A UTILIZAÇÃO DO DESIGN COMO VANTAGEM COMPETITIVA NO SETOR MOVELEIRO DE SANTA MARIA/RS
}

\section{USE OF DESIGN AS COMPETITIVE ADVANTAGE IN THE FURNITURE INDUSTRY AT SANTA MARIA/RS}

\author{
Leoni Pentiado Godoy* E-mail: leoni@smail.ufsm.br \\ Mario Luiz Santos Evangelista* E-mail: mario.santos.evangelista@gmail.com.br \\ Morgana Pizzolato*E-mail: morganapizzolato@ufsm.br \\ Alexandre Rodrigues Ferreira** E-mail: alexandreferreira@unifra.br \\ * Universidade Federal de Santa Maria, Santa Maria, RS \\ ${ }^{*}$ Centro Universitário Franciscano
}

Resumo: Este artigo expõe a contribuição inovadora e dinamizadora dos profissionais do design no setor moveleiro, enfocando o aumento da competitividade da cadeia produtiva do setor. Desta forma, a questão motivadora do estudo busca determinar: como o design, enquanto estratégia, alinhado a qualidade, pode atuar como diferencial competitivo em micro e pequenas empresas do setor moveleiro? Para concretizar o estudo foram realizadas entrevistas individuais com os gestores de indústrias moveleiras e aplicados questionários aos consumidores de móveis na região de Santa Maria, localizada no centro do Estado do Rio Grande do Sul. A pesquisa mostrou que, a procura por mecanismos, que geram competitividade entre as empresas está cada vez mais intensa, e a busca por métodos inovadores para conseguir a eficiência é de grande importância. O design agrega valor ao produto em termos de estética, ergonomia, conforto e funcionalidade, além de ser um elemento muito importante na racionalização da produção.

Palavras-chave: Indústria moveleira. Design. Qualidade. Competitividade.

Abstract: This article shows the contribution of innovative and proactive professional design to increase the competitiveness of the supply chain sector. Thus, the question that motivates the study were: how the design as a strategy, aligned to quality, can act as a competitive to micro and small enterprise in the furniture sector? The study conducted individual interviews with furniture industry managers and used questionnaires to furniture consumers in Santa Maria, located in the center of Rio Grande do Sul State. The research has shown that the search for mechanisms that create competition between companies is increasingly intense and the race for innovative methods to achieve efficiency has great importance. The design adds value to product in terms of aesthetics, ergonomics, comfort and functionality, besides being a very important element in the rationalization of production.

Keywords: Furniture industry. Design. Quality. Competitiveness.

\section{INTRODUÇÃO}

O acirramento da concorrência dos mercados nacional e internacional é cada vez maior. O processo de globalização e a abertura de novos mercados exigem das empresas incrementos na sua competitividade, e postura inovadora frente aos novos 
desafios. A manutenção e conquista de novos mercados requer acrescentar elementos e características que identifiquem e diferenciem produtos e serviços.

$\mathrm{Em}$ alguns segmentos industriais o papel do design tem por característica apenas embelezar o produto previamente planejado, ausentando-o de integração durante as etapas que compreendem o projeto. Esta posição empresarial distancia a verdadeira capacidade de integração e inovação propostas pela gestão do design.

No mercado, as empresas bem sucedidas desfrutam de credibilidade e fidelidade por parte dos consumidores, estabelecendo uma imagem positiva com a utilização do design como ferramenta eficiente para criar e implantar a cultura empresarial. Dessa forma, compreende-se o produto final como manifestação integrada de todas as etapas que correspondem ao desenvolvimento de um produto; refletindo a imagem da empresa através desse.

De acordo com Roese e Gitahy (2004) a busca da adequação da produção de móveis ao poder aquisitivo do consumidor, o conceito de mercado estratificado em nichos por faixa etária, sexo e estilo de vida, são noções que começam a ser introduzidas no setor no final dos anos 60 , mas que só nos anos 80 se difundem amplamente. Na década de 90, com a abertura comercial, as empresas moveleiras, principalmente aquelas voltadas para o mercado de móveis retilíneos, alcançaram melhorias de desempenho significativas a partir da aquisição de tecnologia de ponta, aumento da automação e melhorias nos processos de controle de qualidade (MOTTA, 2004).

O objetivo deste artigo é mostrar a contribuição dos designers no setor moveleiro fornecendo subsídios de ordem teórica e prática para a agregação de valor mediante o uso do design na produção. Deste modo, o design serve como elemento inovador e dinamizador para o aumento da competitividade da cadeia produtiva do setor moveleiro. Contudo, cada organização apresenta necessidades diferentes, podendo supri-la de maneira que se ajuste melhor dentro de suas limitações, entretanto, atendendo as necessidades dos clientes. Desta forma, o estudo coloca em tese a seguinte pergunta: Como o design enquanto estratégia, alinhado a qualidade pode atuar como diferencial competitivo em micro e pequenas 
empresas do setor moveleiro? A importância deste estudo é contribuir para a identificação das necessidades dos clientes do setor moveleiro.

A estrutura desse artigo contempla: na Seção 2, design e qualidade presentes em um plano de ação para obter vantagem competitiva por meio do produto projetado pelo designer, introduzindo inovação e, principalmente, atendimento as expectativas do cliente, visando sua maior satisfação; a Seção 3 apresenta as vantagens competitivas e a prática do design nas empresas de pequeno porte, bem como, a estratégia de diferenciação de seus produtos, onde o design visa à contínua inovação dos mesmos, além do atendimento das necessidades de seus clientes; na Seção 4, a relação entre a indústria moveleira internacional e nacional nas empresas de pequeno porte apresentando as principais exigências dos dois mercados; na Seção 5, os procedimentos metodológicos, a serem utilizados para alcançar os objetivos propostos; na Seção 6, a discussão dos resultados conforme entrevista com os gestores e a partir do ponto de vista dos consumidores; e na Seção 7, as considerações finais da pesquisa.

\section{DESIGN E QUALIDADE}

Questões referentes a valor estão presentes nas definições atuais de qualidade, porém, outras questões de qualidade, como a redução de desperdício de matéria-prima, de tempo, de recursos humanos e também a otimização do uso dos equipamentos para reduzir custos de produção passaram a fazer parte do significado de qualidade. Bornia (1995) observa que, o desperdício de matéria-prima é aquele em que as mesmas foram despendidas de forma anormal ou acima do estritamente necessário à confecção do produto. Nas empresas, os conceitos de qualidade estão basicamente voltados ao atendimento e a satisfação das necessidades e expectativas dos clientes.

Essa situação leva as empresas a enfrentar problemas de produtividade e de custos elevados. Esses problemas podem ser associados ao desperdício, sendo que, os custos poderiam ser eliminados se o produto fosse executado corretamente da primeira vez. Eliminando ou reduzindo esses desperdícios a empresa terá 
oportunidade de reduzir custos, aumentar a lucratividade e tornar-se mais competitiva.

Uma empresa interessada em fabricar produtos de qualidade deve realizar ações no sentido de conhecer e atender às reais necessidades de seus clientes. No entanto, as empresas precisam maximizar recursos para melhorar seu desempenho. Isso mostra a importância do designer, que desenvolve novas maneiras de solucionar problemas de desperdícios de matéria prima. Uma contribuição importante é dada por Löbach (2007), de acordo com o autor, o design é uma idéia, um projeto ou um plano para a solução de um problema determinado, cuja corporificação se dá com a ajuda dos meios correspondentes, tornando visivelmente perceptível a solução de um problema.

Embora a noção de atendimento às necessidades do cliente já estivesse presente em trabalhos de Shewhart (1932), foram Deming (1990) e Juran (1990) que desenvolveram o conceito especificando suas dimensões básicas: qualidade do projeto e qualidade em termos de conformidade.

Atender as expectativas dos clientes exige que a empresa esteja sempre monitorando a qualidade no atendimento de suas necessidades, superando essas expectativas, e para tal deve estar empenhada na melhoria contínua de produtos e processos. A satisfação serve para conectar os processos que culminam em compra ou consumo com os fenômenos relacionados com a pós-compra, tais como: mudanças de atitude, compras repetidas e lealdade à marca (CHOl et al., 2008).

$\mathrm{Na}$ ótica de White e Yu (2005), num ambiente competitivo, os lucros de uma empresa podem ser aumentados a partir da diferenciação dos seus produtos ou serviços, buscando a satisfação dos desejos e necessidades do consumidor. Contudo, existem paradigmas em relação à integração do design na gestão da qualidade em organizações de pequeno porte. Existem, em âmbito nacional, muitas interpretações e barreiras impostas pelos gestores, que acreditam que o design é apenas um custo a mais para o produto, mas algumas empresas não analisam por essa ótica. Quanto ao âmbito internacional, esse paradigma está sendo mudado com maior rapidez, particularmente no continente europeu, pois, a administração 
dessas empresas é realizada por pessoas com visão estratégica, ou que possuem cultura empresarial consolidada.

O design deve ser usado porque, segundo Mozota (2002), a empresa deve estar preparada para ter sua imagem comparada à da concorrência e competir no mercado nacional e internacional. $\mathrm{O}$ autor evidencia ainda que, o design atende ao consumidor que aspira por um produto, com qualidade, por um preço menor, além de reduzir os custos de produção e processos e preservar o meio ambiente. A concepção mais básica do design, de acordo com CNI (1996) associa-se a valores estéticos. Ampliando-se tal concepção é possível entender o design como um processo criativo, inovador e provedor de soluções de problemas, de importância fundamental não somente para as esferas produtivas, tecnológica e econômica, mas, também social, ambiental e cultural.

Vale salientar que, até recentemente, os projetos de produtos atendiam unicamente, a função que os produtos tinham para o consumidor, sendo que, o comportamento de compra era orientado para a necessidade de adquirir os objetos. Com o passar do tempo, o design procura conjugar a satisfação do cliente com o lucro da empresa. Com esse intuito, usa a criatividade de forma inovadora para combinar características como desempenho, durabilidade, aparência e custos em um único produto.

De acordo com Rozenfeld e Forcellini (2006), o desenvolvimento de produtos envolve várias atividades a serem realizadas por diversos profissionais de diferentes áreas da empresa, ou seja: marketing, pesquisa e desenvolvimento, engenharia de produto, suprimentos, manufatura e distribuição. Silva Filho (1995) propõe que, para obter melhores níveis de produtividade, se faz necessário que haja o comprometimento de todas as pessoas que contribuem para o desenvolvimento das atividades organizacionais. Para isso, é fundamental a participação do designer e que, este esteja envolvido com o processo.

Neste contexto, o design amplia suas funções e passa atuar como articulador de inovações divulgando o diferencial de qualidade dos produtos e a estratégia competitiva da empresa. Assim, o design como ferramenta estratégica das empresas de pequeno porte, deve conquistar o seu espaço de atuação na estrutura 
organizacional, principalmente nos níveis de atuação administrativa, operacional e estratégica.

\section{VANTAGENS COMPETITIVAS E A PRÁTICA DO DESIGN NAS EMPRESAS DE PEQUENO PORTE}

A vantagem competitiva origina-se do valor criado pela organização e percebido pelos clientes, assim, para uma empresa obter vantagem competitiva, ela precisa adotar estratégias para lidar com as forças competitivas existentes no mercado, classificando-se em: rivalidade entre os concorrentes e entrada de novos concorrentes no mercado, ameaça dos produtos substitutos, poder de negociação dos compradores e dos fornecedores (PORTER, 1999).

Para Ansoff (1965) a vantagem competitiva está relacionada percepção de tendências de mercado frente aos concorrentes. No entender de Ohmae (1978) a vantagem competitiva passa por um processo evolutivo que envolve a unidade de negócio como um todo, e não apenas para um produto.

Besanko, Drannove e Shanley (2000) interpretam vantagem competitiva como a obtenção de um resultado ótimo da empresa no uso racional combinado de seus recursos. Assim, Porter (1992) e Roquebert, Phillips e Westfall (1996), citam que a escolha estratégica é fundamental e impacta no desempenho organizacional, e a adequação das estratégias organizacionais ao ambiente externo torna-se o princípio da competitividade. Mintzberg, Ahsltrand e Lampel (1998) abordam que existe a teoria competitiva na indústria e teoria da competitividade territorial. A primeira refere-se aos estudos na indústria de Porter $(1979,1980)$ e a segunda baseia-se nos estudos de Cox (1997), Dyer (1996) e Storper (1997), que identifica o envolvimento da comunidade local e seus atores, onde o território em que atua a organização define como a mesma opera.

A gestão estratégica passa a ser uma vantagem competitiva quando identifica, desenvolve e obtém vantagens na conquista dos negócios (SOUTH, 1981). Dessa forma, Aaker (1984) expõe que escolher uma estratégia de negócios envolve a decisão de onde competir e o desenvolvimento de uma vantagem competitiva sustentável. Quando a estratégia alcança certo objetivo, essa passa a 
ser uma vantagem competitiva para a organização, por delinear objetivos estabelecidos previamente ou decorrentes de observações, informações e decisões ao longo do tempo. Ghemawat (1986) demonstra que fontes de vantagem competitiva originam-se de fatores que envolvem a inovação de produto, processos de produção ou capacidade de marketing das organizações.

A diferenciação dos produtos e a especialização em um determinado segmento de mercado são estratégias genéricas, ou seja, são métodos para lidar com as forças competitivas. Por meio dessas estratégias, o design encontra caminhos para se incorporar nas práticas empresariais.

O design reduz custos, na medida em que seu trabalho é orientado para satisfação dos desejos e necessidades solicitadas pelo cliente. Mas, é na estratégia de diferenciação do produto que, o design se configura como um instrumento de importância fundamental, pois essa estratégia genérica atende também à de segmentação. Os produtos absorvem a subjetividade dos valores simbólicos e de comunicação do design. Os usuários destes produtos se identificam com as referências simbólicas e passam a fazer parte do grupo social de consumo de um determinado produto e, ao compartilhar determinado estilo de vida, os consumidores determinam a segmentação de mercado.

O design busca fundamentalmente maximizar a capacidade de um produto, atender às necessidades dos clientes, sejam necessidades estéticas, funcionais, econômicas, etc. Assim, um design mal concebido deixa de aproveitar uma série de potencialidades do produto, potencialidades que muitas vezes podem ser decisivas na competição no mercado.

$\mathrm{Na}$ indústria moveleira, apesar dos progressos que ocorreram nos últimos anos, as empresas ainda continuam concorrendo através de custo e não por diferenciação, a grande maioria de seus produtos é copiada, não possuindo a singularidade necessária para Ihe atribuir uma identidade própria. Essa característica é comum, também, entre grandes empresas, que ainda desconsideram a abrangência da atuação do profissional de design, essencialmente, os benefícios que o resultado do seu trabalho pode trazer para a sua empresa (SILVA, 2006). 
Existem várias formas de relacionar o design e as empresas de pequeno porte, mas é evidente que, não existe uma cultura consolidada nessa relação. $O$ design normalmente está associado, no caso dessas empresas, ao elevado custo, e não como investimento. Assim, o desenvolvimento de produtos fica ligado à cópias adaptadas ou, até por meio de projetos híbridos, os quais une a cópia, no entanto com pequenas alterações. Finalmente, o design pode servir como instrumento na formação de novos hábitos do consumidor, tornando o mercado mais exigente e forçando o aumento da qualificação das empresas que competem no mercado.

Silva e Santos (2005) constataram que, os conceitos de estratégias são poucos conhecidos. Os autores explicam que, essa limitação de ausência de conhecimento é devida ao fato de existirem poucos estudos, na área de planejamento estratégico, voltados para as pequenas e médias empresas. Os conceitos de estratégia competitiva e produção ainda não estão inseridos na cultura empresarial, principalmente, as empresas de porte, médio ou pequeno. Para Silva e Santos (2005) a utilização das estratégias competitivas e a integração com as estratégias de produção trazem produtos bem concebidos forçando a retirada de produtos sem inovações. Além disso, pode-se dizer que a prática do design nas empresas de pequeno porte pode ser implantada com relativa facilidade.

\section{RELAÇÃO ENTRE A INDÚSTRIA MOVELEIRA INTERNACIONAL E NACIONAL}

Santi (2000) clarifica que a industrialização do mobiliário brasileiro teve sua origem em 1875 gerada pela produção de artesões, sendo que a maioria deles era italiana. Estas empresas se caracterizavam pela estrutura familiar com produção artesanal, geradas pelo aumento do fluxo imigratório no final do século XIX e início do século $X X$.

O Brasil, diferentemente de outros países como Estados Unidos, Alemanha e Itália apresenta elevada verticalização da produção, não havendo especialização na produção em partes, componentes ou produtos semi-acabados, resultando em um aumento dos custos industriais e inúmeras etapas em um mesmo processo produtivo e em uma mesma planta industrial. 
Quanto ao desenvolvimento dos móveis, segundo Silva (2006), as empresas copiam modelos oferecidos no mercado mundial, sendo que são poucas as empresas que procuram criar um design próprio. A propósito do meio ambiente, é necessário esclarecer que, a cadeia produtiva do setor apresenta-se pouco organizada, isso acarreta dificuldade de implantação de programas ambientais que englobam todos os elos da cadeia. Na presença de iniciativa de maior integração vislumbra-se melhoria através de programas estimulados pelas entidades representativas e pelos órgãos governamentais (ABIMOVEL, 2005).

Devido à interferência do governo, que se insere nos programas ambientais com o intuito de avaliar e apontar possíveis contribuições na atividade do setor, algumas empresas apontam dificuldades na implantação desses programas ou até desconhecem a existência dos mesmos. No entanto, observa-se, principalmente, na pequena e média empresa, uma apreensão gerencial com a reformulação dos processos produtivos para acompanhar essas transformações mundiais e tornar o desenvolvimento e a fabricação de produtos mais competitivos.

\section{PROCEDIMENTOS METODOLÓGICOS}

Para realizar esta pesquisa utilizou-se a metodologia quali-quantitativa de acordo com as etapas descritas na sequência.

Etapa 1 - Seleção das empresas para a pesquisa: primeiramente foram selecionadas, aleatoriamente, três empresas de pequeno porte que fazem parte da Rede Moveleira de Santa Maria.

Etapa 2 - Realização das entrevistas e da análise dos dados qualitativos: a partir da seleção das empresas foram realizadas entrevistas individuais semi-estruturadas com seus gestores. O conteúdo das entrevistas foi direcionado a aspectos sobre a estrutura do setor, design, qualidade, aspectos referentes à sustentabilidade e a expectativa do setor.

De acordo com Ribeiro e Milan (2004), as entrevistas individuais consistem num método para coleta de dados qualitativos e têm sido consideradas entre os principais métodos de coleta de dados de pesquisas qualitativas. Nas entrevistas 
individuais, entrevistador e entrevistado ficam frente a frente, oportunizando, dessa forma, explorar em profundidade o objeto da pesquisa.

As entrevistas individuais podem ser conduzidas de forma semi-estruturada e não estruturada. Na primeira forma de condução, existe um roteiro básico, na qual o entrevistador pode acrescentar perguntas de esclarecimento. Na segunda forma de condução das entrevistas individuais, o objeto da pesquisa é explicado e, a partir daí, entrevistado e entrevistador vão conduzindo o diálogo (LAVILLE; DIONNE, 1999; RIBEIRO; MILAN, 2004).

Como as entrevistas individuais têm uma abordagem qualitativa, o grupo de pessoas escolhido não precisa ser estatisticamente representativo da população, mas deve fornecer informações úteis a respeito dela. Para tanto, Ribeiro e Milan (2004) sugerem estratificar a população e escolher indivíduos que representem e conheçam esses estratos. O número de entrevistados não deve ser grande e nem precisa ser definido a priori, mas deve ser controlado pelo fluxo de informações recebidas.

Etapa 3 - Definição da amostra, aplicação do questionário para os consumidores e análise dos resultados: com base nas entrevistas com os gestores foram definidos os bairros de Santa Maria que seriam aplicados os questionários para buscar a opinião dos consumidores a respeito da importância do uso do design como fator diferencial. O questionário foi aplicado em quatro bairros da cidade de Santa Maria responsáveis por $90 \%$ do poder de compra de móveis, de acordo com a opinião dos gestores. O questionário foi respondido de forma espontânea e preenchido pelos próprios consumidores. O tamanho da amostra foi definido com base nos registros da Prefeitura Municipal de Santa Maria, a partir do censo municipal de 2007. Segundo Lopes (2008), é importante para a pesquisa a definição de uma amostra de tamanho adequado, garantindo a representatividade da população. Dessa forma, foi utilizada a Equação 1 (TRIOLA, 2005) e os dados da Tabela 1 para determinar o tamanho da amostra.

$n=\frac{\left[Z_{\alpha / 2}\right]^{2} \hat{p} \hat{q}}{E^{2}}$

(Equação 1)

Revista Produção Online, Florianópolis, SC, v.12, n. 3, p. 779-805, jul./set. 2012. 
Onde: $\alpha$ é o nível de significância $(0,05)$;

$Z_{\alpha / 2}$ é o valor de $Z$ para $\alpha=0,05(1,96)$;

$\hat{p}$ é a estimativa pontual da proporção populacional $(0,9)$;

$\hat{q}$ é $(1-\hat{p})$;

E é o erro máximo da estimativa $(0,03)$ e;

$n$ é o tamanho da amostra.

A Tabela 1 apresenta os dados relativos à população dos bairros de Santa Maria, de acordo com o censo municipal de 2007 , que concentram $90 \%$ do poder de compra de móveis. Também apresenta o tamanho total da amostra (385) e o tamanho da amostra para cada bairro, de acordo com a população. As entrevistas foram realizadas nos meses de maio, junho e primeira quinzena de julho de 2008, o pesquisador visitava a residência aguardando o preenchimento do questionário.

\begin{tabular}{lrr}
\multicolumn{3}{l}{ Tabela 1 - População dos bairros do estudo } \\
\hline & População & $n$ p/ bairro \\
\hline Centro & 29.330 & 170 \\
Camobi & 13.334 & 78 \\
Patronato & 10.553 & 62 \\
N.S. de Lourdes & 12.896 & 75 \\
$\quad$ Total & $\mathbf{6 6 . 1 1 3}$ & $\mathbf{3 8 5}$ \\
\hline
\end{tabular}

Fonte: Elaborada pelos autores

\section{DISCUSSÃO E APRESENTAÇÃO DOS RESULTADOS}

Esta seção apresenta e discute as análises realizadas nas etapas 1 e 3 referentes, respectivamente, a análise dos dados qualitativos e quantitativos. Os primeiros, obtidos das entrevistas individuais com os gestores das empresas; os outros, obtidos da aplicação dos questionários junto aos consumidores de móveis.

\subsection{Discussão dos resultados conforme entrevista com os gestores}

Segundo os entrevistados, Santa Maria possui aproximadamente 180 empresas atuando no setor moveleiro. Destas, somente, $22 \%$ estão formalmente 
legalizadas na prefeitura municipal. Na visão dos entrevistados, Santa Maria, por estar localizada na região central do Estado (localização estratégica) e ter vias de acesso para escoamento da produção, pode obter vantagens competitivas através da formação de um cluster, havendo redução de custos e aumento da eficiência nos processos produtivos.

Do ponto de vista desses gestores, existem choques de cultura empresarial que são ocasionados pela falta de visão sistêmica, pois o setor não apresenta uma configuração homogênea. Há empresas com capacidade tecnológica que projetam e executam produtos de qualidade superior, reconhecidos pelo mercado. Entretanto, outras empresas apresentam lacunas em seus níveis tecnológicos, gerando produtos com pouca aceitação e credibilidade no mercado, outras apresentam baixos níveis tecnológicos, que geram produtos de menor qualidade e pouca aceitação no mercado.

Para Camara e Serconi (2006), o fato das organizações estarem inseridas em um ambiente complexo e propício a incerteza, que instiga a formação de elos e o comportamento inovador. Fornecedores, clientes, parceiros, governo e as organizações expandiram seu grau de interação, modificando valores, produtos, serviços e informações. A proximidade geográfica de empresas setorialmente especializadas, no caso de pequenas e médias organizações, tem possibilitado um ambiente apropriado para o desenvolvimento e fortalecimento das mesmas.

Quanto à dificuldade para a produção seriada de móveis, destaca-se o problema da falta de recursos para compra de novas tecnologias. Um dos maiores obstáculos concentra-se nas operações de furação que utilizam tecnologias avançadas como o CNC (Comando Numérico Computadorizado), devido aos altos custos. Como o sistema atual de furação e corte da maioria dessas organizações é manual, o sistema automatizado economizaria o tempo de execução dessas atividades. Outra questão abordada é a falta de canais de comercialização, devido à característica de cunho familiar das organizações, o principal meio de propaganda é informal, sendo realizado através dos próprios clientes, principal meio de propaganda é via boca a boca. Empresas familiares sofrem com a falta de plano de 
expansão, em geral passam de geração para geração e não existe o interesse de se aprimorar tecnologicamente.

Quanto ao sistema produtivo, tem-se caracterizado pela lentidão dos processos em razão da não padronização dos mesmos, gerando dificuldades de otimização dos negócios. Os gestores, por sua vez, salientam que esse fato apresenta algumas vantagens como: personalização de serviços, estrutura comercial direta e baixo custo. Tal fato ocorre devido à maior proximidade com o cliente, pois, o mesmo tem maior participação e interação no processo produtivo. Neste contexto, o desafio está em padronizar os diferentes tipos de processos aliados a produtos personalizados, criando desta forma um sistema produtivo otimizado. Esse sistema gera redução de desperdício tanto de matéria prima quanto de mão-de-obra. Como resultado, tem-se 0 aumento das possibilidades de ganho em razão da personalização gerada para atender as necessidades específicas dos clientes.

Owens (2006) afirma que são várias as razões para a lentidão em sistemas produtivos, tais como: carência na definição de solicitações de produtos e projetos de gerenciamento, incertezas tecnológicas e a falta de apoio dos gestores e recursos. As maiores preocupações surgem, incluindo o gerenciamento, o estilo organizacional, a falta de atenção a detalhes, o suporte limitado para inovação, a falta de pensamento estratégico e a baixa capacidade de manufatura.

Em 2003, entre 40\% e 50\% das empresas da Rede Moveleira de Santa Maria possuíam um projetista próprio no início do funcionamento do núcleo. Atualmente, $60 \%$ das empresas possuem um projetista, pois perceberam a importância dessa função. A maioria das empresas informais, e grande parte das formais, são compostas por marceneiros que executam seus desenhos manualmente, sem possuir conhecimentos específicos como acontece com os projetistas especializados.

Evidencia-se também a falta de investimentos em softwares legalizados para a realização dos serviços, bem como a falta de marketing, ou seja, as empresas estão na chamada "zona de conforto". Para Leslie e Reimer (2003) tecnologias novas de produção, como softwares específicos facilitam o desenvolvimento de produtos, porque possuem ferramentas versáteis, que substituem peças piloto, 
podendo modificar a variedade de cores além do dimensionamento. No atual mercado competitivo, os fabricantes de mobiliários precisam se adaptar as constantes inovações de produtos, e perceber que a obsolescência é uma ameaça para sua sobrevivência.

Com relação aos aspectos referentes à responsabilidade sócio-ambiental, verifica-se que, no contexto atual, Santa Maria não dispõe de uma empresa que trate dos resíduos industriais do setor moveleiro, fazendo com que todo esse resíduo seja alocado no lixão municipal, sem nenhum tipo de tratamento adequado. As empresas recebem a madeira beneficiada, evitando que resíduos maiores sejam gerados. Em relação a maravalha (serragem mais grossa), normalmente é doada para as pessoas carentes, que as utilizam nos fornos a lenha em suas casas, ou instituições como a Associação dos Pais e Amigos dos Excepcionais (APAE).

A criação do MDF foi fundamental para a expansão da indústria moveleira, pois esse é fundamental para substituição de algumas madeiras serradas, como a imbuia, o loro, o mogno e o marfim, considerados nobres, cujas extrações são proibidas. Um modo de aproveitamento sustentável dos retalhos de MDF, desenvolvido por um dos gestores, foi a criação de uma chapa com esses retalhos, que possui valor $60 \%$ menor do que uma chapa normal e durabilidade maior.

Foi mencionado pelos gestores que as obrigações com a sustentabilidade da produção e origem da madeira ficam a cargo dos fornecedores. Existe uma relação de confiança, se a empresa for autuada por utilizar madeiras de origem proibida, esta será a responsável.

Em geral, o cliente não tem preocupação por questões de conformidade das empresas para com o meio ambiente no momento da compra de um produto, pois, este acredita que as mesmas, estão agindo conforme as questões legais e também de acordo com suas responsabilidades sócio-ambientais.

A expectativa de crescimento do setor moveleiro em Santa Maria é pequena, pois estão penetrando no mercado empresas de renome nacional, as quais dispõem de novas tecnologias consideradas essenciais para projetos inovadores. Os gestores das empresas entrevistados apontam que, empresas da região continuam com a 
visão tradicional, de que as mudanças e as melhorias não influenciam na produtividade e qualidade dos produtos, portanto perderão seu espaço no mercado.

\subsection{Discussão dos resultados a partir da análise da pesquisa no ponto de vista dos consumidores}

A seguir são apresentados os resultados obtidos através da análise dos questionários aplicados aos consumidores para identificar os fatores mais relevantes no momento da compra de móveis planejados na cidade de Santa Maria. Da amostra de 385 entrevistados 54,3\% foram do sexo feminino e 45,5\% masculino.

Observa-se na Figura 1, que 23,4\%, dos 385 entrevistados possuem ensino médio, a mesma proporção também em relação aqueles que possuem o ensino superior incompleto. Apenas 2,60\% possuem o ensino fundamental incompleto. Deste modo, percebe-se que, a maior proporção da amostra ficou entre as pessoas com ensino médio completo, superior incompleto e completo, que totalizou $67,8 \%$.

Figura 1 - Nível de escolaridade dos respondentes
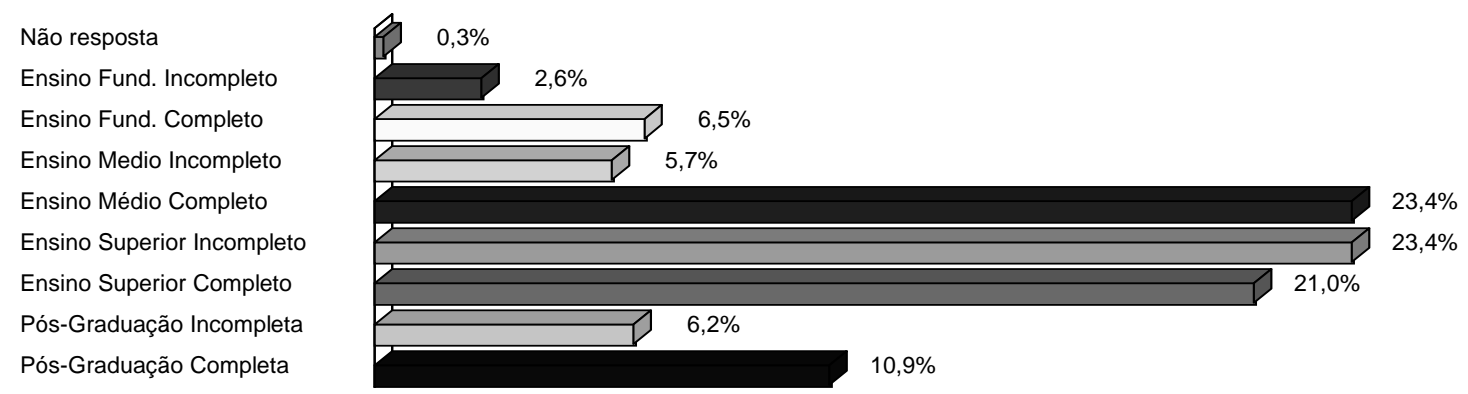

Fonte: Elaborada pelos autores

A Figura 2 mostra que 23,90\% dos entrevistados possuem renda familiar até 10 salários mínimos, enquanto 11,4\% possuem renda familiar superior a 13 salários mínimos. Assim, a pesquisa abordou pessoas de diferentes segmentos sociais, 0 que se mostrou muito importante, pois as análises refletem percepções de diferentes classes de renda salarial.

Dos 385 entrevistados, 278, ou seja, 72,2 \% mostraram ter conhecimento da prática de design, enquanto $27,8 \%$ mostraram desconhecer a prática, ou seja, a maior parte da amostra conhecia o uso de design na elaboração de produtos. Deve- 
se levar em consideração que o objetivo da questão era apenas definir se o entrevistado conhecia ou não a prática de desenvolvimento de produtos com uso da ferramenta design, não levando em consideração o nível de conhecimento sobre o assunto. Assim, pode-se concluir que em geral, de algum modo, as pessoas conhecem o que é design, cabe então descobrir se ele influi no poder de decisão na hora da compra.

Figura 2 - Renda familiar dos respondentes por domicílio

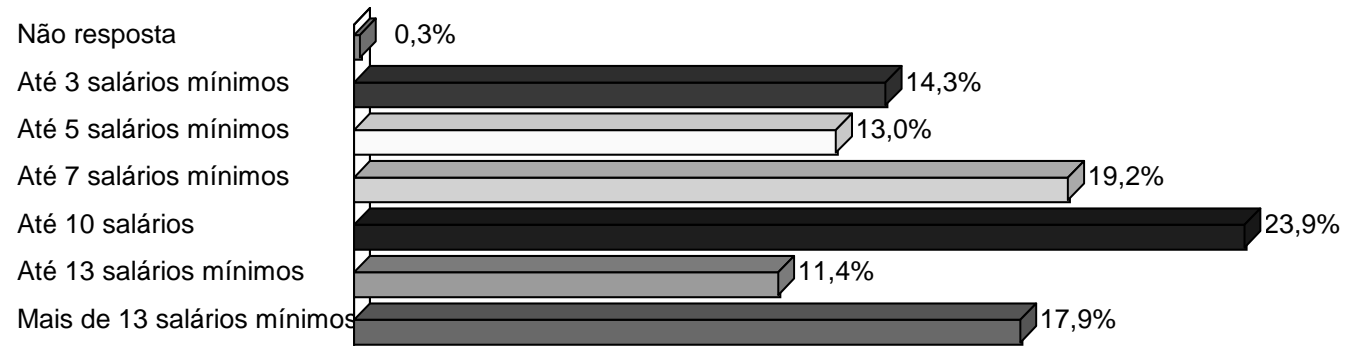

Fonte: Elaborada pelos autores

Quanto à variável "influência do design na escolha de um produto" $88,3 \%$ dos entrevistados afirmaram que o design influencia na compra de um produto e $11,7 \%$ responderam que o design não influencia na compra de um produto.

Observa-se na Figura 3, que quanto à variável importância do design nos produtos 51,2\% dos 385 entrevistados julga ser importante e 30,6\% muito importante. Henver (2004) reconhece a importância de profissionais qualificados na área do design e destaca que projetar produtos úteis é complexo devido à necessidade de avanços na área da criatividade e domínio de áreas na qual a teoria existente ainda é insuficiente.

Figura 3 - Importância do design em sua opinião

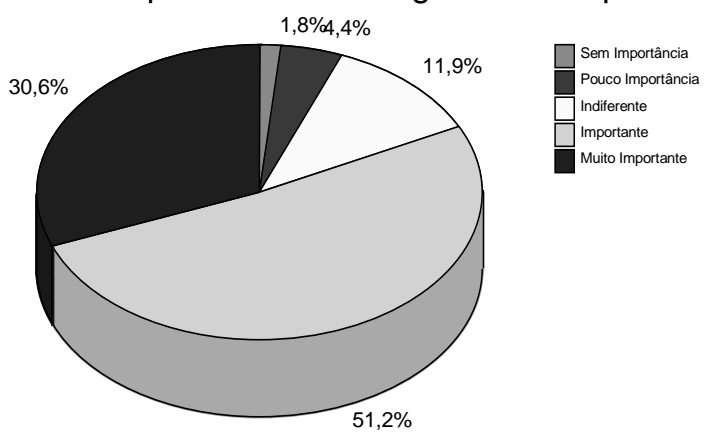

Fonte: Elaborada pelos autores

Revista Produção Online, Florianópolis, SC, v.12, n. 3, p. 779-805, jul./set. 2012. 
Quando questionados em relação à variável "levar em consideração o uso de materiais ambientalmente corretos na confecção dos produtos" $83,6 \%$ responderam que levam em consideração esta variável no momento da compra e apenas 16,4 \% com opinião contraria. Constatou-se ainda que 1,82\% dos entrevistados, ou seja, 7 (sete) observaram que falta a empresa divulgar melhor a procedência dos materiais utilizados na confecção do produto.

Os aspectos referentes à responsabilidade socioambiental correspondem a um caminho inerente às políticas internas das empresas, que apresentam uma forte ligação com o ambiente externo. Portanto, as organizações precisam ressaltar a importância de uma estratégia que esteja voltada para a questão socioambiental, onde as organizações possam obter uma parcela significativa de mercado, atendendo consumidores que estão cada vez mais preocupados as questões de meio ambiente e este ligado a produtos ecologicamente corretos (FERREIRA; JOÃO; GODOY, 2008b).

Com relação à análise do grupo "Grau de importância que é definido no momento da compra de um móvel", definiu-se que os parâmetros seriam estabelecidos sob uma notação de 1 (Sem Importância) a 5 (Muito Importante). Observa-se, na Tabela 2, que o item de menor importância na ótica dos consumidores é a variável "origens culturais", 33 \% responderam que este aspecto é indiferente. Quanto aos gestores, evidenciaram que empresas do setor acreditam que a produção segundo as origens culturais é a melhor estratégia de conquistar mercado. 
Tabela 2 - Valor percentual das variáveis quanto ao grau de importância

\begin{tabular}{|c|c|c|c|c|c|}
\hline Variáveis/escala & $\begin{array}{l}\text { Sem } \\
\text { Importância }\end{array}$ & $\begin{array}{l}\text { Pouco } \\
\text { Importante }\end{array}$ & Indiferente & Importante & $\begin{array}{c}\text { Muito } \\
\text { Importante }\end{array}$ \\
\hline$N^{\circ}$ funcionalidades produto & $2,10 \%$ & $6,20 \%$ & $11,70 \%$ & $44,40 \%$ & $35,60 \%$ \\
\hline Estética & $1,50 \%$ & $2,00 \%$ & $7,80 \%$ & $55,20 \%$ & $33,50 \%$ \\
\hline Praticidade & $1,30 \%$ & $1,30 \%$ & $4,90 \%$ & $43,90 \%$ & $48,60 \%$ \\
\hline Estilo & $1,00 \%$ & $2,10 \%$ & $12,50 \%$ & $45,50 \%$ & $39,00 \%$ \\
\hline Qualidade & $0,30 \%$ & $1,30 \%$ & $2,90 \%$ & $30,60 \%$ & $64,90 \%$ \\
\hline Origens culturais & $13,20 \%$ & $11,90 \%$ & $33,00 \%$ & $28,10 \%$ & $13,80 \%$ \\
\hline Divulgação & $3,90 \%$ & $8,10 \%$ & $18,40 \%$ & $43,90 \%$ & $25,70 \%$ \\
\hline Durabilidade & $0,00 \%$ & $0,55 \%$ & $1,45 \%$ & $30,40 \%$ & $67,60 \%$ \\
\hline Segurança & $0,30 \%$ & $1,00 \%$ & $1,30 \%$ & $31,70 \%$ & $65,70 \%$ \\
\hline Custo/beneficio & $0,50 \%$ & $1,30 \%$ & $2,10 \%$ & $34,30 \%$ & $61,80 \%$ \\
\hline Satisfação & $0,00 \%$ & $0,30 \%$ & $1,80 \%$ & $37,90 \%$ & $60,00 \%$ \\
\hline Imagem da empresa & $3,40 \%$ & $3,10 \%$ & $14,0 \%$ & $47,30 \%$ & $32,20 \%$ \\
\hline $\begin{array}{l}\text { Procedência da matéria- } \\
\text { prima }\end{array}$ & $4,40 \%$ & $3,70 \%$ & $19,50 \%$ & $43,60 \%$ & $28,80 \%$ \\
\hline Prazo de entrega & $0,30 \%$ & $0,80 \%$ & $3,60 \%$ & $37,60 \%$ & $57,70 \%$ \\
\hline $\begin{array}{l}\text { Pós-compra (assistência } \\
\text { técnica) }\end{array}$ & $0,30 \%$ & $1,00 \%$ & $1,50 \%$ & $35,60 \%$ & $61,60 \%$ \\
\hline $\begin{array}{l}\text { Diferentes possibilidades de } \\
\text { adaptação }\end{array}$ & $0,30 \%$ & $3,40 \%$ & $11,60 \%$ & $43,40 \%$ & $41,30 \%$ \\
\hline
\end{tabular}

Fonte: Elaborada pelos autores

Quanto ao perfil dos consumidores de móveis os gestores afirmam que existem dois perfis de cliente quanto às exigências em relação ao produto: o cliente mais culto, que em geral, possui capacidade de entender o processo produtivo, que leva em conta as análises ergonômicas e as questões de praticidade; e o cliente que foca no custo-benefício.

Stefano, Chapoval e Godoy (2008) reforçam que o comportamento do consumidor é um tema chave de sustentação de toda a atividade mercadológica realizada com o intuito de desenvolver, promover e vender produtos. É evidente que, para otimizar a eficácia e a eficiência das atividades de marketing é preciso procurar entender como os consumidores tomam suas decisões para adquirir ou utilizar os produtos.

O item mais importante, no ponto de vista dos consumidores, é o aspecto "durabilidade" os quais $67,60 \%$ responderam como sendo muito importante. Outros itens como "segurança", "qualidade" e "custo/beneficio" também foram apontados como muito importante.

Essas variáveis só serão bem adequadas ao produto, com a realização de um bom projeto de design, que privilegie essas variáveis, pois o primeiro passo no 
entendimento e controle dessas variáveis é a compreensão do relacionamento de causa e efeito, que está inserido no seu processo de produção. Para Moreira (2001) o desenvolvimento do produto se preocupa em atender as expectativas e as necessidades de seus consumidores, assim como também, atender as especificações técnicas do projeto final.

A Tabela 3 apresenta cinco valores: mínimo, máximo, média, desvio-padrão das médias e coeficiente de variação, do questionário aplicado aos consumidores para as variáveis do grupo "Grau de importância que é definido no momento da compra de um móvel".

Quanto aos coeficientes de variação encontrados para os entrevistados, para as dezesseis questões, obteve-se um percentual inferior a $30 \%$, sendo, estas médias representativas para o conjunto de dados analisado, isto é, os valores são considerados importantes para os entrevistados. Na variável "origens culturais" o coeficiente de variação encontrado foi superior a $30 \%$, isto é, as respostas dos entrevistados encontram-se altamente dispersas.

Tabela 3 - Desvio padrão, média, valor máximo e mínimo e coeficiente de variação

\begin{tabular}{lccccc}
\multicolumn{1}{c}{ Variáveis } & $\begin{array}{c}\text { Valor } \\
\text { mínimo }\end{array}$ & $\begin{array}{c}\text { Valor } \\
\text { máximo }\end{array}$ & Média & $\begin{array}{c}\text { Desvio } \\
\text { Padrão }\end{array}$ & $\begin{array}{c}\text { Coeficiente } \\
\text { de variação* }\end{array}$ \\
\hline Durabilidade & 2 & 5 & 4,65 & 0,53 & 0,11 \\
Segurança & 1 & 5 & 4,62 & 0,60 & 0,13 \\
Qualidade & 1 & 5 & 4,59 & 0,64 & 0,14 \\
Satisfação & 2 & 5 & 4,58 & 0,54 & 0,12 \\
Pós-compra (assistência técnica) & 1 & 5 & 4,57 & 0,61 & 0,13 \\
Custo/beneficio & 1 & 5 & 4,56 & 0,66 & 0,14 \\
Prazo de entrega & 1 & 5 & 4,52 & 0,63 & 0,14 \\
Praticidade & 1 & 5 & 4,37 & 0,75 & 0,17 \\
Diferentes possibilidades de adaptação & 1 & 5 & 4,22 & 0,80 & 0,19 \\
Estilo & 1 & 5 & 4,19 & 0,81 & 0,19 \\
Estética & 1 & 5 & 4,17 & 0,78 & 0,19 \\
No funcionalidades produto & 1 & 5 & 4,05 & 0,95 & 0,23 \\
Imagem da empresa & 1 & 5 & 4,02 & 0,94 & 0,23 \\
Procedência da matéria-prima & 1 & 5 & 3,89 & 1,01 & 0,26 \\
Divulgação & 1 & 5 & 3,79 & 1,04 & 0,27 \\
Origens culturais & 1 & 5 & 3,17 & 1,21 & 0,38 \\
\hline
\end{tabular}

Fonte: Elaborada pelos autores

NOTA: *O Coeficiente de Variação é a razão entre o desvio-padrão e a média e está apresentado como porcentagem (\%). Se CV: menor ou igual a 15\% - Baixa dispersão - homogênea, estável. Entre 15 e 30\% - Média dispersão. Maior que 30\% - Alta dispersão - heterogênea.

Em relação à média de cada variável, ainda na Tabela 3 é possível verificar que, a questão da segurança, com média de 4,62, ganha destaque quando, pais se 
preocupam com a segurança de seus filhos pequenos. Isso acontece, pois projetos com falhas produzem móveis com cantos pontiagudos ou geram partes cortantes, que aumentam a possibilidade de acidentes. Esse quesito perde apenas para a durabilidade do produto, variável com maior média de importância para os entrevistados. A ergonomia, no ponto de vista de Nunes e Franzoni (2004), ligada à gestão dos processos e da qualidade nas organizações faz com que se analise esses processos enfatizando a organização como um todo, relacionando assim as necessidades de todos os usuários envolvidos no processo, podendo estas necessidades ser de diversos níveis. A variável praticidade, apontada como importante pelos consumidores (média de 4,37), também se encontra ligada à ergonomia de produto, pois um bom projeto vislumbra tanto questões de conforto, de manutenção, limpeza e uso dos mesmos.

Quanto à estética (média 4,17) destaca-se que um produto pode ser considerado com boa estética e não possuir um estilo definido, podendo perder o foco, como por exemplo, móveis clássicos, contemporâneos, etc. A estética está diretamente ligada ao estilo, e nesse, cabe ao profissional de design configurar 0 foco certo.

Com relação à variável diferentes possibilidades de adaptação (média $4,22)$, destaca-se que, é mais um motivo para as organizações tomarem frente no processo de produção de móveis modulares, que se caracterizam pela flexibilidade de serem adaptados de acordo com a necessidade do consumidor. Os móveis modulares permitem produção seriada, com menores custos. Segundo Hexcel (2003) o produto apresenta vantagens de uso, devido à maior racionalidade na ocupação dos espaços e permite que um ambiente seja adquirido gradativamente.

Outro aspecto importante, a destacar é a variável imagem da empresa, enfatizada como importante para os consumidores (média 4,02). Toda empresa que investe em design, seja ela grande, média, pequena ou micro, torna sua marca conhecida de forma positiva no mercado pela qualidade do que produz, visto que, seus produtos agregam funcionalidade, beleza, conforto, racionalidade e respeito ao meio ambiente, além de características inovadoras e tecnologicamente mais avançadas. 
A variável custo/benefício, também foi apontada como muito importante pelos consumidores, (média 4,56), ocorre quando a empresa possui um processo produtivo otimizado, fazendo com que, os custos e gastos fiquem minimizados, refletindo no preço final do produto a ser comercializado pela empresa.

Dando continuidade a análise é possível observar que, $83,3 \%$ dos respondentes conhecem a prática de design e possuem pós-graduação incompleta, enquanto $60 \%$ não conhecem, e possuem ensino fundamental incompleto (Tabela 4).

Tabela 4 - Cruzamento das variáveis "você conhece a pratica de design de produtos" com "grau de escolaridade"

\begin{tabular}{l|c|c}
\hline $\begin{array}{l}\text { Conhece a prática de design de produtos? } \\
\text { Escolaridade }\end{array}$ & Sim & Não \\
\hline Ensino Fundamental Incompleto & $40,0 \%$ & $60,0 \%$ \\
\hline Ensino Fundamental Completo & $52,0 \%$ & $48,0 \%$ \\
\hline Ensino Médio Incompleto & $59,1 \%$ & $40,9 \%$ \\
\hline Ensino Médio Completo & $70,0 \%$ & $30,0 \%$ \\
\hline Ensino Superior Incompleto & $77,8 \%$ & $22,2 \%$ \\
\hline Ensino Superior Completo & $75,3 \%$ & $24,7 \%$ \\
\hline Pós-Graduação Incompleta & $83,3 \%$ & $16,7 \%$ \\
\hline Pós-Graduação Completa & $78,6 \%$ & $21,4 \%$ \\
\hline Total & $72,2 \%$ & $27,8 \%$ \\
\hline
\end{tabular}

Fonte: Elaborada pelos autores

Em relação à renda familiar, a Tabela 5 apresenta que, $87 \%$ dos entrevistados, que escolhem produtos com design aprimorado e ambientalmente correto, com um preço superior aos normais possuem uma renda familiar superior a 13 salários mínimos. No geral, os entrevistados estão dispostos a pagar mais caro por um produto com bom design. Evidencia-se que, independentemente da estratificação social, a importância do design é considerada relevante.

Tabela 5 - Cruzamento das variáveis "qual produto você escolhe para comprar" com "renda familiar"

\begin{tabular}{l|r|r}
\hline $\begin{array}{l}\text { Qual produto você escolhe para comprar? } \\
\text { Renda familiar }\end{array}$ & $\begin{array}{r}\text { Produto } \\
\text { com design }\end{array}$ & $\begin{array}{c}\text { Produto } \\
\text { sem design }\end{array}$ \\
\hline Até 3 salários mínimos & $72,7 \%$ & $27,3 \%$ \\
\hline Até 5 salários mínimos & $72,0 \%$ & $28,0 \%$ \\
\hline Até 7 salários mínimos & $71,6 \%$ & $28,4 \%$ \\
\hline Até 10 salários mínimos & $83,7 \%$ & $16,3 \%$ \\
\hline Até 13 salários mínimos & $84,1 \%$ & $15,9 \%$ \\
\hline Mais de 13 salários mínimos & $87,0 \%$ & $13,0 \%$ \\
\hline Total & $79,0 \%$ & $21,0 \%$ \\
\hline
\end{tabular}

Fonte: Elaborada pelos autores

Revista Produção Online, Florianópolis, SC, v.12, n. 3, p. 779-805, jul./set. 2012. 
Essa disposição de pagar mais por um produto com design bem elaborado, reflete nas variáveis, as quais, os consumidores foram abordados, pois ao conhecerem exatamente os níveis que compõem um produto de nível superior, eles aumentaram seu nível de exigências diante de uma decisão de compra de móveis.

Portanto, as práticas de design apresentam fundamental importância na gestão, valorizá-lo é garantir competitividade ao produto e desenvolvimento à empresa, desde que realizado por profissionais experientes, que saibam adaptar recursos da empresa, necessidade do mercado e metas a serem alcançadas.

\section{CONSIDERAÇÕES FINAIS}

A procura por mecanismos que geram competitividade entre as empresas esta cada vez mais intensa e a corrida por métodos inovadores para conseguir a eficiência é de grande importância. A indústria brasileira de móveis precisa estruturar-se com urgência e impor uma tendência própria que lhe permita reocupar espaços perdidos e ingressar em novos mercados.

Evidencia-se que há necessidade de conscientização dos empresários de Santa Maria sobre a importância do investimento em design como fator de competitividade. Percebe-se que o design é o fator principal nas empresas de pequeno porte no setor moveleiro permitindo que, por um lado, este desenvolva vantagens competitivas e, por outro, agregue maior valor ao produto.

Nesta pesquisa buscou-se entender como estas empresas atuam em relação, aos fatores relacionados ao design, e também estendendo a discussão acerca das questões ambientais, como a sustentabilidade. Foram entrevistados os gestores da Rede Moveleira de Santa Maria com a finalidade de entender a ótica dos consumidores. Evidenciou-se que do ponto de vista de alguns dos gestores o design é caracterizado como algo que encarece a produção incorrendo em custos desnecessários para as empresas.

O estudo evidencia que, as micro e pequenas empresas do setor, só irão consolidar o uso do design quando estiverem realmente perdendo espaço no mercado para as que incorporaram o design na sua cultura. Essa atitude 
conservadora, no ponto de vista de alguns gestores, em parte relaciona-se ao paradigma que está associado à visão de curto prazo que vê o design apenas como um custo. Enquanto, numa visão de longo prazo, o custo inicial do produto será diluído no aumento das vendas e na consolidação da credibilidade da empresa, tanto na parte de qualidade do produto, como nas questões de responsabilidade sócio-ambiental. Observa-se que, a realidade do setor moveleiro demanda grande aprimoramento em toda sua cadeia produtiva, isso porque, a indústria moveleira, na sua quase totalidade, é composta de empresas familiares e de capital inteiramente nacional, conforme foi evidenciado nos resultados da pesquisa de campo realizada em Santa Maria - RS.

Isso ocorre devido à falta de visão e atitudes empreendedoras dos gestores, cujas empresas são caracterizadas como de caráter familiar, onde os investimentos em pesquisa e inovação são colocados a margem, sendo que, em sua grande maioria, a produção é configurada como artesanal. O papel da gestão de design, neste setor, caracteriza-se como potencializador das tecnologias disponíveis para o desenvolvimento de novos produtos, na operacionalização e organização das empresas, e principalmente buscar a excelência na prestação de serviços.

O design tem também uma enorme importância na gestão. Valorizar o design é garantir competitividade ao produto e desenvolvimento à empresa, desde que realizado por profissionais capacitados, que saibam adequar recursos da empresa, necessidades do mercado e metas a serem alcançadas. A fabricação de objetos com design criativo requer investimentos, e ainda são poucas as empresas que pensam em uma Gestão do Design. Assim, o grande desafio do profissional é conscientizar o empresário de que um objeto sem design é um produto de risco. $\mathrm{O}$ design agrega valor ao produto em termos de estética, ergonomia, conforto e funcionalidade, além de ser um elemento muito importante na racionalização da produção. O designer, no contexto do mercado globalizado, deve estar apto a atuar com visão estratégica, contribuindo para aumentar a competitividade do produto brasileiro.

As empresas que virão de outros locais para investir na região, as quais possuem forte capital para investimento, provavelmente já trabalham com essa 
metodologia. Decorrente disso, as empresas da região que não se adaptarem ao contexto atual, onde as mudanças são contínuas, dificilmente manter-se-ão no mercado, e as que sobreviverem será apenas num curto prazo, porque ficarão defasadas, tanto pelo aspecto tecnológico, como no que tange a cultura empresarial.

Portanto, é de suma importância por parte das organizações perceberem que para inovar, são necessários desafios e atitudes empreendedoras, essas atitudes e desafios podem ser concernentes ao emprego da ferramenta design na gestão de qualidade e nos projetos de produtos como diferencial competitivo. Como foi evidenciada na pesquisa, sua utilização é perceptível e não menos aspirada independentemente da estratificação social, ou seja, um bom projeto de produto tem condições de abranger e atender as expectativas e necessidades de uma parcela com maior significância, não somente dos consumidores, mas de todas as partes interessadas.

\section{REFERÊNCIAS}

AAKER, D. A. How to select a business strategy. California Management Review, v. 26, n. 3, p. 167-181, 1984.

ABIMÓVEL. Associação Brasileira das Indústrias do Mobiliário. (2005).

Disponível em: <http://www.abimovel.org.br>. Acesso em: 09 jul. 2008.

ANSOFF, H. I. Corporate strategy. Harmondsworth: Penguin, 1965.

BESANKO, D.; DRANOVE, D.; SHANLEY, M. Economics of strategy. New York: Wiley, 2000.

BORNIA, Antonio Cezar. Mensuração das perdas dos processos produtivos: uma abordagem metodológica de controle interno. Tese (Doutorado) Universidade Federal de Santa Catarina. Florianópolis, 1995.

CAMARA, M, R, G.; SERCONI, L. Gestão empresarial e tecnológica em três clusters moveleiros selecionados no sul do Brasil, Semina: Ciências Sociais e Humanas. Londrina, v. 27, n. 1, p. 35-50, jan./jun. 2006

CHOI, J.; SEOL, H.; LEE, S.; CHO, H.; PARK, Y. Customer satisfaction factors of mobile commerce in Korea, Internet Research, v.18, n. 3, p. 313-335, 2008. 
CONFEDERAÇÃO NACIONAL DA INDÚSTRIA (CNI). Design para a competitividade: recomendações para a política industrial no Brasil, relatório síntese. Rio de Janeiro. 1996.

COX, K. R. Spaces of globalization: reasserting the power of the local. New York: The Guilford Press, 1997.

DEMING, William Edwards. Qualidade: a revolução da administração. Rio de Janeiro: Marques-Saraiva, 1990. 370p.

DYER, J. H. Specialized supplier networks as a source of competitive advantage: evidence from the auto industry. Strategic Management Journal, v. 17, n. 1, p. 271291, 1996.

FERREIRA, A. R.; JOÃO, D. M.; GODOY, L. P. A competitividade das organizações sob a ótica interativa de cadeias produtivas sustentáveis e ecodesign. In: Anais do IV Congresso Nacional de Excelência em Gestão - CNEG, Niterói, RJ, 2008b.

GHEMAWAT, P. Sustainable advantage. Harvard Business Review, v. 64, n. 5, p. 53-69, 1986.

HENVER, A. R. et al. Design science in information system research. MIS Quarterly, 2004.

HEXCEL, A. E. A estratégia da Todeschini para alcançar e sustentar vantagem competitiva. ENCONTRO DA ASSOCIAÇÃO NACIONAL DE PÓS-GRADUAÇÃO E PESQUISA EM ADMINISTRAÇÃO - EnANPAD. Anais... 2003.

JURAN, J. M. (1990). Juran Planejando para a Qualidade. São Paulo: Pioneira. LAVILLE, Christian; DIONEE, Jean. A construção do saber: manual de metodologia de pesquisa em ciências humanas. Tradução de Heloísa Monteiro e Francisco Settineri. Porto Alegre: Editora Artes Médicas Ltda; Belo Horizonte: Editora UFMG, 1999.

LESLIE, D.; REIMER, S. Fashioning furniture: restructuring the furniture commodity chain, Royal Geographical Society (with The Institute of British Geographers), $\mathrm{n}$. 35, v.4, 2003.

LÖBACH, Bernd. Design industrial. São Paulo: Edgard Blücher, 2007.

LOPES, Luis Felipe D. estatística e qualidade \& produtividade: cálculos. Disponível em: <http://felipelopes.com/CalculoAmostra.php>. Acesso em: 19 out. 2008.

MINTZBERG, H.; AHLSTRAND, B.; LAMPEL, J. Strategy safari: a guided tour through the wilds of strategic management. New York: Free Press, 1998. 
MOTTA, F. G. Relatório setorial preliminar. FINEP, Rio de Janeiro, 2004.

MOREIRA, D. A. Administração da produção e operações. São Paulo: Pioneira Thomson Learning. 2001.

MOZOTA, Brigite Borja de. Design management. Paris: Éditions d'Organization, 2002.

NUNES, E. L. S. e FRANZONI, A. M. B. Gestão do processo aliada a ergonomia para microempresas. ENCONTRO NACIONAL DE ENGENHARIA DE PRODUÇÃOENEGEP, 24., 2004. Anais...Florianópolis, 2004.

OWENS, J. D. Why do some UK SMEs still find the implementation of a new product development process problematical? An exploratory investigation. Management Decision, v. 45, n. 2, p. 235-251, 2006.

OHMAE, K. Effective strategies for competitive success. The McKinsey Quarterly, v. 20, n. 2, p. 50-59, 1978.

PORTER, M. Vantagem competitiva: criando e sustentando um desempenho superior. Rio de Janeiro: Campus, 1992.

Competitive strategy: techniques for analyzing industries and competitors. New York: Free Press, 1980.

. The structure within industries and companies'performance. The Review of Economics and Statistics, v. 61, n. 2, p. 214-227, 1979.

. Estratégia competitiva: técnicas para análise da indústria e da concorrência. 8. ed., Rio de Janeiro: Ed. Campus, 1999.

RIBEIRO, J. L. D. (Ed); MILAN, G. S. (Ed). Planejando e conduzindo entrevistas individuais. Porto Alegre: FEENG/UFRGS, 2004.

ROESE, M; GITAHY, L. M. C. Globalização, indústria tradicional e gênero: a indústria de móveis de madeira em Bento Gonçalves/RS. In: ENCONTRO ANUAL DA ASSOCIAÇÃO NACIONAL DE PÓS-GRADUAÇÃO E PESQUISA EM CIÊNCIAS SOCIAIS - ANPOCS, 28,. 2004. Anais...Caxambu / MG, 2004.

ROQUEBERT, J. A.; PHILLIPS, R. L.; WESTFALL, P. A. Markets vs. management: what 'drives' profitability? Strategic Management Journal, v. 17, n. 8, pp. 653-664, 1996.

ROZENFELD, H.; FORCELLINI, F. A. Gestão de desenvolvimento de produtos: uma referência para a melhoria do processo. São Paulo: Saraiva, 2006. 542 p. 
SANTI, M. A. Contribuição aos estudos sobre as origens da produção seriada do mobiliário no Brasil - a experiência Móveis Cimo S/A. 175f. Dissertação (Mestrado) Faculdade de Arquitetura e Urbanismo, Universidade de S. Paulo, 2000.

SILVA FILHO, J. L. F. Gestão participativa e produtividade: uma abordagem da ergonomia. Tese (Doutorado em Engenharia de Produção). Universidade Federal de Santa Catarina. Florianópolis. 1995.

SILVA, P. R. Design, inovação e arranjos produtivos moveleiros das micro e pequenas empresas: o caso dos pólos pernambucanos. 2006. 137f. Dissertação (Mestrado em Design) - Universidade Federal de Pernambuco, Recife, 2006.

SILVA, Eliciane Maria da e SANTOS, Fernando César Almada. Análise do alinhamento da estratégia de produção com a estratégia competitiva na indústria moveleira. Prod. [online]. 2005, v.15, n.2, p. 286-299. Disponível em: $<$ http://www.scielo.br/scielo.php?script=sci_arttext\&pid=S0103$65132005000200012 \&$ Ing=pt\&nrm=iso $>$. ISSN 0103-6513. http://dx.doi.org/10.1590/S0103-65132005000200012.

SOUTH, S. E. Competitive advantage: the cornerstone of strategic thinking. The Journal of Business Strategy, v. 1, n. 4, p. 15-25, 1981.

STEFANO, N.; CHAPOVAL NETO, A.; GODOY, L. P. Explorando conceitos e modelos sobre o processo de decisão de compra do consumidor em função da mudança de hábito alimentar. IV Congresso Nacional de Excelência em Gestão CNEG, Niterói, Rio de Janeiro 2008.

SHEWHART, W. A. Economic control of quality of manufactured product. New York: Van-Nostrand Reinhold, Princeton, 1932.

STORPER, M. The regional world: territorial development in a global economy. New York: The Guilford Press, 1997.

TRIOLA, M. F. Introdução à estatística. Rio de Janeiro: LTC, 2005.

WHITE, C.; YU, Yin-Ting. Satisfaction emotions and consumer behavioral intentions, Journal of Services Marketing, v.6, n.19, p.411-420, 2005.

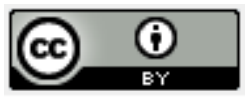

Artigo recebido em 13/04/2011 e aceito para publicação em 29/03/2012. 